\title{
GLAZER, MYRON
}

\section{THE RESEARCH ADVENTURE, PROMISE AND PROBLEMS OF FIELD WORK}

N. Y.: Randon Houss, 1973.

Myron Glazer nos presenta en su libro una problemática vivida profundanente por el sociólogo o investigador social al confrontar sus bases teóricas con el campo práctico de estudio. Esta problemática es tan antigua como las Ciencias Sociales. Ha existido desde que se intentó penetrar en las estructuras sociales para desmarañar y ganar conocimientos, en todos los niveles posibles, de las interacciones bumanas existentes en las diversas instituciones y estratos sociales. Si bien los problemas presentados por Glazer eran conocidos, quizá no se babían confrontado tan clatamente con la perspectiva que él lo hace. Ciertamente han habido controversias, diálogos y artículos sobre el tema. Así como libros que sistemáticamente han pre-

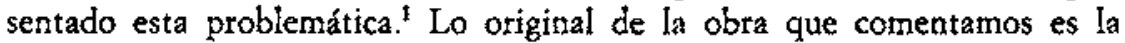

1. Cereseto, S., «Dialogue between a Human Being and a Social Scientist." Et $\mathrm{Al}$, vol. $2 \mathrm{n}^{\circ} 2$ (fall 1969), pp. 26-28.

Dahrendorf, R., (ed.) «Values and Social Sciences» edited in Essays in the Theory of

Society. Stanford, California: Stanford University Press, 1969. pp. 1+18.

Gouldnet, A. W., "Anti-Minotaur: The Myth of a Value.Free Sociology." Social

Problems, vol. 9 n. 3 (Winter 1962), pp. 199.213.

Lynd, R. S., Knowledge for What? N. J.: Princenton University Press, 1967. 
reflexión sobre los problemas concretos que el investigador social palpa y siente una vez está trabajando en investigación directa.

The Research Adventure es un libro interesante por la finalidad que pretende, por la ternática y por la perspectiva en que ésta es presentada.

El libro fue escrito pretendiendo ser una ayuda para los cursos de introducción a la sociología. Tanto $M$. Glazer como Peter I. Rose ${ }^{2}$ querían que estos cursos tuvieran dos partes: una histórica y otra metodológica. Este libro salía al paso para ayudar a realizar la segunda parte.

En primer término ya es loable un curso organizado de esta forma. Para todos son harto conocidos los cursos introductorios que quedan reducidos al enfoque histórico. Es fundamental una perspectiva evolutiva-ideológica en el campo de las ciencias sociales; pero es igualmente fundamental una vertebración histórico-metodológica, sobre todo para aquellos que, por su profesión, deberán intentar comprender o investigar las estructuras sociales existentes.

Libros sobre métodos y técnicas de investigación social existen y muy acertados, tanto por su contenido como por su claridad, cara a una orientación y formación de nuevos investigadores sociales. Glazer presenta un libro de metodología (no exhaustivo como es lógico) complementario en su perspectiva al contenido de otros muchos libros de métodos y técnicas de investigación. En general los manuales de metodología presentan técnicas y métodos tratados objetivamente y de forma general con ejemplos tomados de investigaciones realizadas. The Researcb Adventure nos presenta la parte cultural, la problemática humana, los valores y la ética que el investigador confronta, o debe confrontar, teniendo en cuenta su equipo de investigación, los sujetos de la investigación, quién la promueve y qué finalidad se pretende.

La tradición sociológica americana, especialmente la de los años 40 a 60 , es principalmente una búsqueda del rol que el sociólogo, como científico, tiene. Como Horowitz piensa, se estableció una fuerte cortiente que

Lundberg, G. A., Can Science Save Us? N. J.: Longmans, Green and Cm., 1947.

Sherif, $M$, "If the Social Scientist is to be more than a mere Thechnician." Journal of Social Issues, vol, $24 \mathrm{n}: 1$ (1968), pp. 41.61.

Los libros aquí presentados son de gran calidad intelectual. La lista podría ser interminable. El libro aquí teseñado es uno más en plantear la cuestión ética del sociólogo.

2. Peter A. Rose es el «Consulting Editor» del libro, profesor como Glazer de Simith College. 
trataba de identificar las ciencias sociales no sólo con las ciencias objetivas, sino que pretendían ser neutrales y libres de valores eludiendo toda problemática ética. En general la sociología americana funcionalista se ha considerado científica y por ello reclama ser neutral y libre de valores.

Glazer, siguiendo la línea opuesta a la sociología estructural-funcional, plantea la problemática ética y valorativa: todo investigador debe ser consciente para definit su postura, no sólo al trazar los objetivos que pretende desde su mesa de trabajo, sino también al encontratse inmerso en el campo de investigación. Además debe estat abierto a cambios cuando nuevos elementos de juicio van apareciendo. Un ejemplo claro es el estudio realizado sobre el Viet-Nam por A. T. Rambo en los años 60. Diez años después declara su equivocación reconociendo que éticamente no debió actuar como lo hizo. ${ }^{3}$

Glazer va suscitando toda la problemática ética y valorativa, a través de una serie de etapas que el investigador social atraviesa en el campo de la investigación. Estas etapas tal como están presentadas en el libro son:

- Decidir el proyecto y la metodología; considerando el problema de cómo ser aceptado y establecer una identidad personal al mismo tiempo que se tiene presente, en todo momento, la suspicacia que se crea en los sujetos estudiados.

- Aprender la forma para introducirse en el campo de trabajo, cuidando de no olvidar el rol de investigador. A veces reacciones ante problemas de injusticia social convierten al investigador en un activista.

- Al estudiar temas o puntos delicados, la resistencia en los sujetos es intensificada y la finalidad que el investigador pretende puede ser tergiversada.

- Dimensión de reciprocidad. ¿A quién debe lealtad el investigador? En general (en USA) los estudios son pagados por los sectores dominantes. Glazer hace notar que así es para ellos fácil escapar del escrutinio de los investigadores sociales y, en cierta manera, dirigir y utilizar la investigación. La responsabilidad del investigador es

3. Horowitz, I. L., Introduction to The New Sociology. Horowitz, I. L. (ed.) N. Y.: Oxford University Press, 1971. 
The Research Adventure, Promise...

grande: estamos ante el problema de «Knoledge for what?" y «Knowledge for whom? "s.

Aparte de que la temática de The Researcb Adventure es presentada con una perspectiva útil y conflictiva, introduce al lector a una serie de conocidos y no tan conocidos estudios sociales que hacen claros y patentes sus objetivos teóricos.

MONTSERRAT ROCA TRESEMS 